\title{
Thiomersal Keratoconjunctivitis, Frequency, Clinical Spectrum and Diagnosis
}

\author{
N. WILSON-HOLT and J. K. G. DART \\ London
}

\begin{abstract}
Summary
Thiomersal keratoconjunctivitis is a common problem in soft contact lens wearers, accounting for thirty two $(10 \%)$ of three hundred and twelve consecutive referrals for contact lens related problems to an out patient department. The clinical findings in 55 patients are described, of which 42 show the 'typical' appearance of the condition. This consists of non-specific conjunctival changes, limbal follicles, superficial punctate keratopathy and superior corneal epithelial opacity. Thirteen atypical cases are presented, demonstrating superior limbitis occurring in isolation, coarse punctate keratopathy, severe keratopathy with visual loss, pseudo-dendritic corneal lesions, acute conjunctival hyperaemia without keratopathy. Symptoms were also seen in two patients who were hard lens wearers. In such atypical cases, diagnosis may be difficult but can be aided by the use of topical challenge with thiomersal.
\end{abstract}

Thiomersal keratoconjunctivitis (TKC) is a common complication of contact lens wear. Although thiomersal hypersensitivity is often manifested as a distinctive condition, a number of different patterns of clinical disease have been described. ${ }^{1,2}$ These can be confused with other external eye disease.

The aims of this study were to determine the frequency of the disease amongst cosmetic contact lens users attending a clinic for treatment, and the different patterns of TKC and the proportion of TKC patients presenting with atypical disease.

\section{Methods}

A retrospective survey was carried out of all new patients attending a clinic for advice about lens related complications to determine the proportion with TKC. These patients were all phakic, and were wearing lenses for simple refractive errors. Additional cases of
TKC from our files were included to demonstrate the clinical spectrum of disease.

In each case, the history, clinical features and time course to resolution were recorded. Cases suspected of being TKC, but who did not have the characteristic clinical appearances, were given a topical challenge in one eye. Thiomersal $0.005 \%$ in isotonic saline was given four times daily for up to 3 days. Positive responses usually developed within hours when the challenged eye demonstrated bulbar conjunctival hyperaemia; this was often associated with mild discomfort. There were no late responses and no other adverse reactions were recorded.

\section{Results}

The records of 312 patients presenting consecutively to a clinic for advice about contact lens related problems were analysed. The prevalence of these problems is: shown in Table I. 
Table I Prevalence of various conditions in 312 patients presenting consecutively to the contact lens department for advice about contact lens related problems.

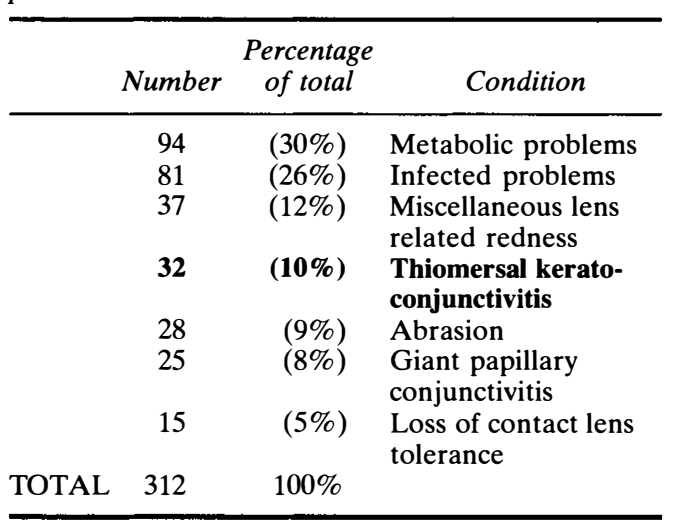

In addition to patients having the features of TKC, obtained from the above analysis, additional cases were recruited to illustrate the clinical spectrum of the disease. Fifty five patients were included, of whom 42 had the 'typical' appearances of the condition, and 13 having atypical features. The results are summarised in Table II.

\section{Typical Features}

The clinical feature of the typical presentation of thiomersal keratoconjunctivitis were found in 42 of our patients. These included conjunctival hyperaemia, with a mixed follicular and papillary response. However, the most striking findings in a well developed case were in the superior limbus and cornea, with limbal hyperaemia, associated with punctate staining of the limbus with fluoroscein, and a keratopathy, extending down from the upper limbus, often in the shape of an inverted triangle. The epithelium in these cases was opaque and contained microcysts and infiltrates as well as staining with fluoroscein and rose bengal. A pannus was present in well developed cases. (Figs. 1a and b). The time taken for resolution of clinical signs ranged from three weeks to nine months with a mean of 4.2 months. The management was avoidance of thiomersal solutions and contact lenses; no topical treatment was used. Topical challenge was performed in 16 patients with the typical appearance, all of whom demonstrated a posi- tive response with no prolonged adverse reaction.

\section{Atypical Presentations}

The remaining 13 patients demonstrated a different spectrum of clinical features. In two patients the signs were similar to the superior limbic keratoconjunctivitis of Theodore. ${ }^{3}$ Figure 2 shows the superior limbal hyperaemia and oedema with few other signs apart from the pannus, which is often associated with soft lens wear. There was a well developed response to topical challenge in this patient. The time to resolution of signs was six months in this patient, and five months in the other patient.

Three patients had a bilateral coarse punctate keratopathy as the predominant feature. Such corneal changes, which took between six months and nine months to resolve, can be confused with the coarse anterior stromal infiltrates typical of adenovirus keratitis, which may also take months to resolve. All three patients demonstrated a positive response to topical challenge with no adverse reactions. Figures $3 a$ and $b$ show such a case in which a patient, previously diagnosed as having viral keratitis, responded within 12 hours to topical challenge. The focal areas of nonwetting cornea are seen in most cases of thiomersal keratitis.

Severe keratopathy with significant visual loss (a reduction of visual acuity by three or more lines of Snellen) was found in three patients. In such a case (Fig. 4) the keratopathy involved the whole cornea and resulted in permanent stromal opacification, associated with corneal irregularity, irregular astigmatism, and loss of corneal clarity resulting in permanent loss of acuity. To date, in each of the three cases, the clinical signs have essentially remained unchanged. Topical challenge was performed in two of the three patients, both of whom gave a positive response with no adverse reactions.

Dendritic corneal lesions were found in one patient (Fig. 5). Unlike herpetic dendritic lesions, these pseudo-dendrites were bilateral and lacked the terminal bulbs characteristic of herpetic disease. There was mild bilateral conjunctival hyperaemia, and a mild papillary tarsal response. There were no signs of stro- 
Table II DWSCL = daily wear soft contact lens. EWSCL = extended wear soft contact lens.

\begin{tabular}{|c|c|c|c|c|c|c|}
\hline Age & Sex & $\begin{array}{l}\text { History of } \\
\text { lens use }\end{array}$ & $\begin{array}{l}\text { Solutions } \\
\text { cont. thiom. }\end{array}$ & $\begin{array}{l}\text { History of } \\
\text { episode }\end{array}$ & $\begin{array}{l}\text { Clinical } \\
\text { signs }\end{array}$ & $\begin{array}{l}\text { Time to } \\
\text { resolution }\end{array}$ \\
\hline \multicolumn{7}{|c|}{ Typical reactions $(n=42)$} \\
\hline $\begin{array}{l}8-41 \text { yr. } \\
\text { mean } \\
27.3 \mathrm{yr} .\end{array}$ & $\begin{array}{l}24 \mathrm{f} \\
18 \mathrm{~m}\end{array}$ & $\begin{array}{l}7 \text { EWSCL } \\
35 \text { DWSCL } \\
\text { time of wear 3/12- } \\
16 / 12\end{array}$ & $\begin{array}{l}26 \text { 'hydrosoak'1 } \\
16 \text { 'lensrins'2 }\end{array}$ & $\begin{array}{l}33 \text { redness \& } \\
\text { discomfort } \\
9 \text { redness and visual } \\
\text { loss }\end{array}$ & $\begin{array}{l}10 \text { conjunctival } \\
7 \text { corneal } \\
25 \text { both }\end{array}$ & $\begin{array}{l}3 / 52-9 / 12 \\
\text { mean } 4.2 / 12\end{array}$ \\
\hline \multicolumn{7}{|c|}{ Superior limbitis $(\mathrm{n}=2)$} \\
\hline 23 & f & DWSCL for $24 / 12$ & 'hydron’3 & redness \& itching & $\begin{array}{l}\text { conjunctival } \\
\text { hyperaemia; } \\
\text { grey } \\
\text { intraepithelial } \\
\text { opacities } \\
\text { superior } 1 / 3 \\
\text { cornea; pannus+ }\end{array}$ & $6 / 12$ \\
\hline 31 & $\mathrm{~m}$ & DWSCL for $15 / 12$ & 'hydrosoak' & redness \& discharge & $\begin{array}{l}\text { similar signs } \\
\text { confined to } \\
\text { superior } 1 / 3 \\
\text { cornea }\end{array}$ & $5 / 12$ \\
\hline \multicolumn{7}{|c|}{ Coarse punctate keratopathy $(n=3)$} \\
\hline 28 & & DWSCL for $14 / 12$ & 'hydrosoak’ & $\begin{array}{l}\text { intermittent } \\
\text { discomfort }\end{array}$ & $\begin{array}{l}\text { bilateral anterior } \\
\text { stromal } \\
\text { infiltrates }\end{array}$ & $6 / 12$ \\
\hline 21 & m & DWSCL for $29 / 12$ & 'hydron' & $\begin{array}{l}\text { 'recurrent viral } \\
\text { keratitis' }\end{array}$ & $\begin{array}{l}\text { bilateral anterior } \\
\text { stromal } \\
\text { infiltrates }\end{array}$ & $7 / 12$ \\
\hline 34 & m & DWSCL for $24 / 12$ & 'lensrins' & $\begin{array}{l}\text { intermittent blurring } \\
\text { of } \\
\text { vision }\end{array}$ & $\begin{array}{l}\text { bilateral anterior } \\
\text { stromal } \\
\text { infiltrates }\end{array}$ & $9 / 12$ \\
\hline \multicolumn{7}{|c|}{ Severe keratopathy with visual loss $(\mathrm{n}=3)$} \\
\hline 26 & f & DWSCL for $21 / 12$ & 'hydrosoak' & $\begin{array}{l}\text { progressive visual } \\
\text { deterioration }\end{array}$ & $\begin{array}{l}\text { bilateral anterior } \\
\text { stromal opacity } \\
\text { irregular } \\
\text { astigmatism }\end{array}$ & not resolved \\
\hline 31 & m & DWSCL for $24 / 12$ & 'lensrins’ & $\begin{array}{l}\text { progressive visual } \\
\text { deterioration }\end{array}$ & $\begin{array}{l}\text { gross corneal } \\
\text { scarring }\end{array}$ & not resolved \\
\hline 32 & f & DWSCL for $19 / 12$ & 'hydrosoak' & $\begin{array}{l}\text { visual loss \& } \\
\text { discomfort }\end{array}$ & $\begin{array}{l}\text { Salzmannoid like } \\
\text { corneal opacities }\end{array}$ & not resolved \\
\hline \multicolumn{7}{|c|}{ Hard contact lens wearers $(n=2)$} \\
\hline 30 & $\mathbf{m}$ & $\begin{array}{l}\text { HCL for } 18 / 12 \\
\text { (previously worn } \\
\text { DWSCL) }\end{array}$ & 'LC65’4 & discomfort \& redness & $\begin{array}{l}\text { conjunctival } \\
\text { hyperaemia; } \\
\text { superior corneal } \\
\text { infiltrates \& } \\
\text { pannus }\end{array}$ & $4 / 12$ \\
\hline 26 & f & $\begin{array}{l}\text { HCL for } 36 / 12 \text { (never } \\
\text { worn DWSCL) }\end{array}$ & ‘LC65’ & $\begin{array}{l}\text { intermittent } \\
\text { discomfort \& } \\
\text { red eyes }\end{array}$ & $\begin{array}{l}\text { nil, but strongly } \\
\text { +ve to topical } \\
\text { challenge }\end{array}$ & \\
\hline \multicolumn{7}{|c|}{ Dendrite-like corneal changes $(n=1)$} \\
\hline 27 & & $\begin{array}{l}\text { DWSCL for } \\
9 / 12\end{array}$ & 'hydrosoak' & $\begin{array}{l}\text { blurred vision } \\
\& \text { intermittent } \\
\text { discomfort }\end{array}$ & $\begin{array}{l}\text { bilateral } \\
\text { conjunctival } \\
\text { hyperaemia \& } \\
\text { papillary } \\
\text { response; } \\
\text { corneal pseudo- } \\
\text { dendrites }\end{array}$ & $3 / 12$ \\
\hline \multicolumn{7}{|c|}{ Acute 'red eye' $(n=2)$} \\
\hline 29 & $\mathbf{m}$ & DWSCL for $18 / 12$ & 'hydrosoak' & $\begin{array}{l}\text { 'recurrent' } \\
\text { conjunctivitis }\end{array}$ & $\begin{array}{l}\text { bilateral bulbar } \\
\text { conjunctival } \\
\text { hyperaemia; no } \\
\text { corneal signs }\end{array}$ & $1 / 52$ \\
\hline 25 & f & DWCSL for $15 / 12$ & 'soflens's & $\begin{array}{l}\text { 'recurrent' } \\
\text { conjunctivitis }\end{array}$ & $\begin{array}{l}\text { bilateral bulbar } \\
\text { conjunctival } \\
\text { hyperaemia; no } \\
\text { corneal signs }\end{array}$ & $1 / 52$ \\
\hline
\end{tabular}




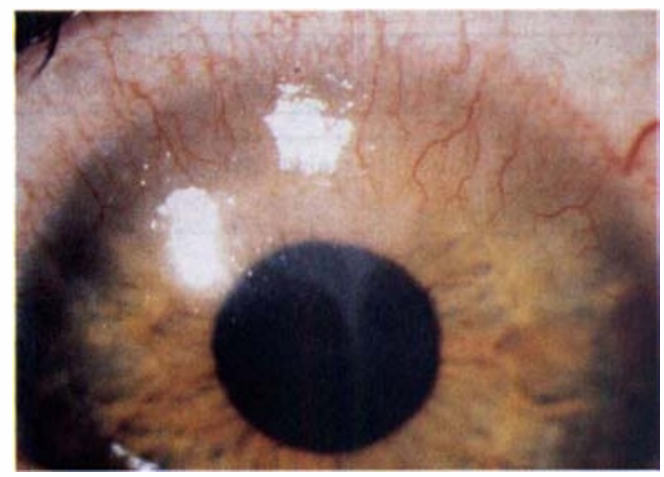

Fig. 1a

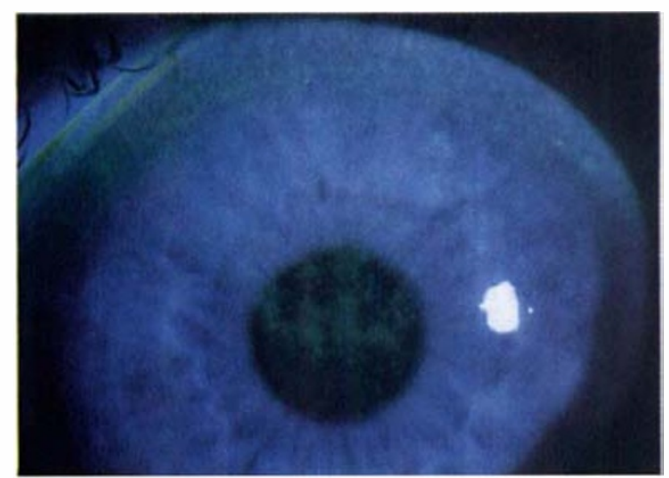

Fig. 1b

Fig. 1 (a) and (b) Showing the features of typical TKC with marked pannus and irregular corneal epithelium which stains with fluoroscein.

mal or endothelial disease in either eye. In this patient, no attempt was made to reproduce the condition with topical challenge. Following cessation of lens wear, the dendritic lesions resolved after three months.

Two patients in our series were hard lens wearers, both using a wetting solution containing thiomersal. One of the patients had a previous history of soft contact lens wear, whilst the other patient had never worn a soft lens. Both were suffering from lens intolerance and red eyes until the wetting solution was changed to one without thiomersal. Later, one of these patients responded rapidly to topical challenge with thiomersal (Fig. 6).

The clinical picture resulting from topical challenge was also seen in two soft lens wearers who presented with acute 'red eye' with marked bulbar conjunctival hyperaemia but no other signs of thiomersal keratoconjunctivitis. Both of these patients had been mistakenly diagnosed has having bacterial conjunctivitis which had been treated with topical antibiotics preserved with thiomersal.

\section{Discussion}

Thiomersal keratoconjunctivitis constitutes $10 \%$ of those seen in our survey of patients attending the contact lens clinic. Any practitioner who sees patients with lens related disease will encounter thiomersal keratoconjunctivitis, and should maintain a high index of suspicion.

There is evidence that thiomersal is a common cause of delayed hypersensitivity. ${ }^{4-10}$ This subject has been well reviewed by Mondino, ${ }^{11}$ and the evidence is both clinical and experimental.

Firstly, patients respond to minute concentrations of thiomersal after long periods of exposure. Once they have responded, exposure results in a rapid onset of symptoms and signs. This phenomenon is used in the

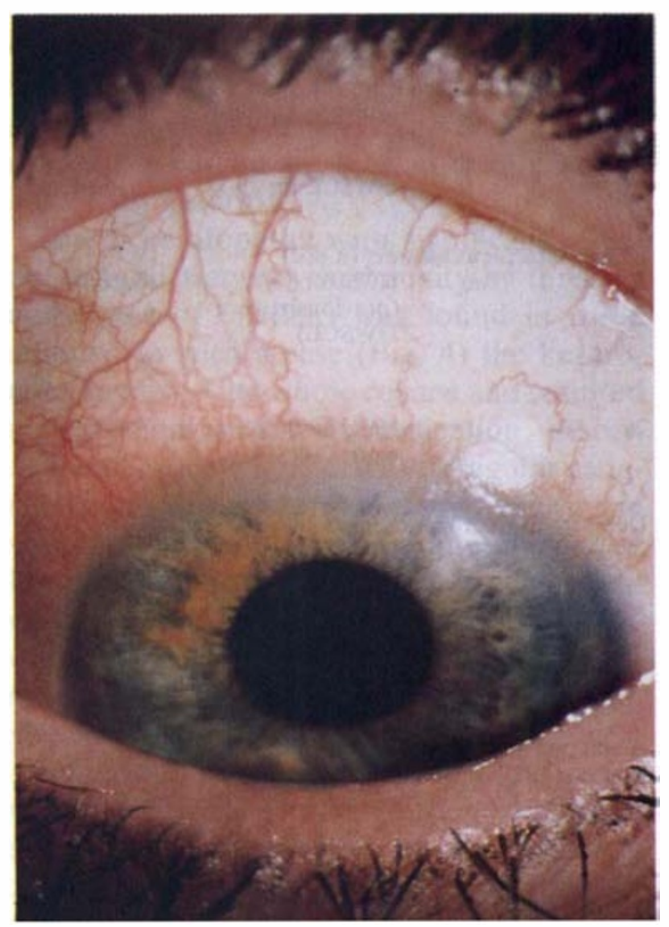

Fig. 2 'Gelatinous swelling' of the superior limbus in a case of thiomersal related superior limbitis. 


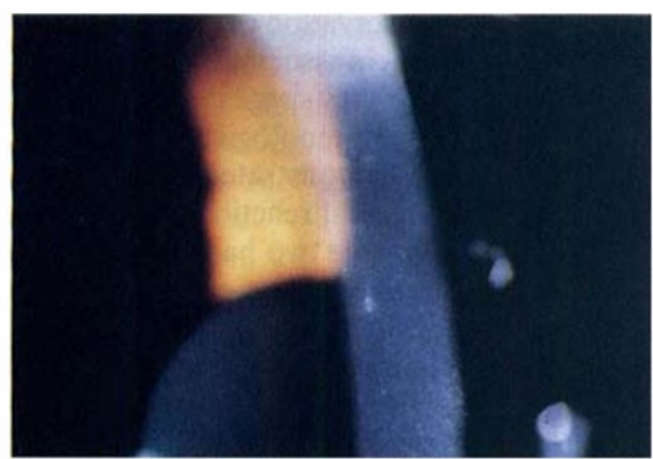

Fig. 3a

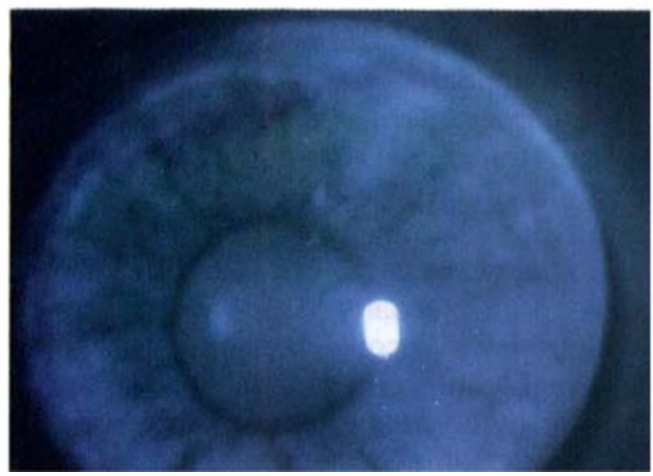

Fig. 3b

Fig. 3 (a) and (b) Coarse punctate keratopathy persisting two months after last exposure to thiomersal. These lesions occur in the superficial stroma and stain with fluoroscein.

topical challenge test described above. These findings are typical of hypersensitivity as opposed to toxicity because there is no evidence of dose dependency. Secondly, there is the cytological evidence that Langerhans cells are present in limbal and adjacent tissues, ${ }^{12}$ such cells have been implicated in cutaneous 'contact' hypersensitivity to a variety of chemicals. ${ }^{13}$ However, it should be noted that the results of skin testing and ocular challenge to thiomersal are not always consistent. ${ }^{1}$ Thiomersal keratoconjunctivitis is common in our practice. This concurs with studies in which the incidence of skin hypersensitivity to thiomersal, as measured by patch testing, varied from 6.6 to $8 \%$ in the U.S.A. ${ }^{46}$ to as high as $25 \%$ in Sweden. ${ }^{7,8}$ These local differences probably depend on differences in exposure to thiomersal which is widely used as a preservative in vaccines and topical antiseptics, as well as ophthalmic preparations. ${ }^{7}$ In one series ocular sensitivity was strongly associated with skin sensitivity, ${ }^{2}$ but in another there was an infrequent association. ${ }^{1}$

The mechanism of ocular hypersensitivity to thiomersal has not been elucidated. It would appear that hydrogel contact lenses absorb highly water soluble thiomersal which is then continually released from the lens allowing prolonged contact with the eye, thereby precipitating a local delayed hypersensitivity reaction, initiated by sensitised $\mathrm{T}$ lymphocytes.

The classical presentation of thiomersal hypersensitivity has been well described, and is difficult to confuse with any other cause of contact lens related disease in soft lens wearers. However, there are many other manifestations that have received less attention in the literature. Patients may often discontinue lens wear because of ocular irritation that in retrospect was probably due to undiag-

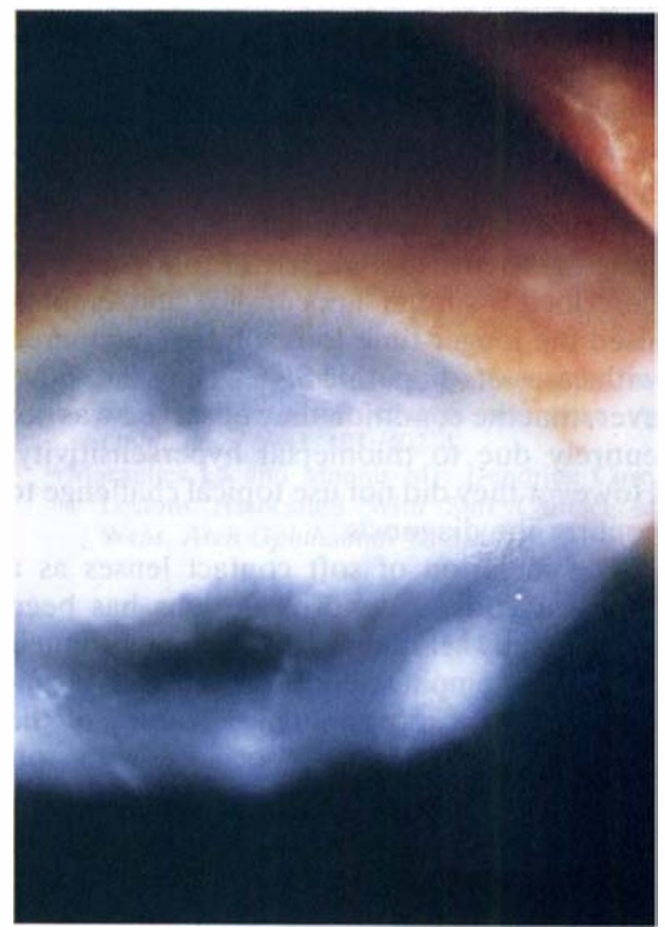

Fig. 4 Gross keratopathy showing stromal opacification leading to irregular astigmatism. 


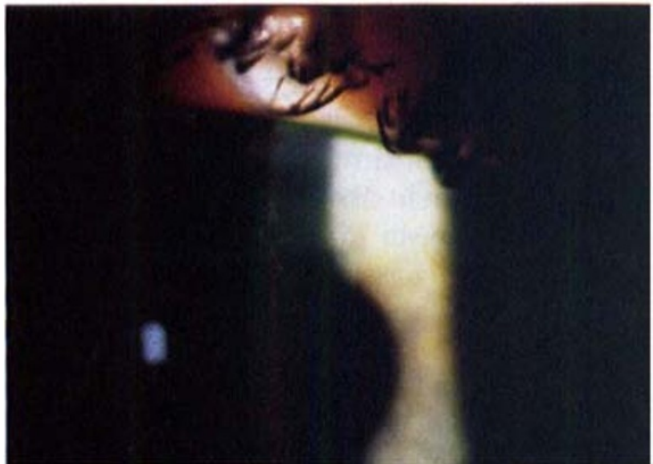

Fig. 5 Dendritic lesion in thiomersal keratopathy staining with fluoroscein.

nosed thiomersal hypersensitivity. After the symptoms have subsided, usually within a few weeks, and the lenses are replaced using the same solutions, severe conjunctival hyperaemia will develop within hours. This is often mistakenly treated as microbial conjunctivitis; on occasion with an antibiotic solution containing thiomersal that will exacerbate the situation further. As both our study and other workers have shown, ${ }^{1}$ this may result in severe keratopathy with permanent loss of visual acuity.

We describe two patients having a clinical picture similar to superior limbic keratoconjunctivitis (SKC) of Theodore, ${ }^{3}$ with signs confined to the superior limbus and upper one third of the cornea. Fuerst et $\mathrm{al}^{14}$ and Stenson ${ }^{15}$ described a similar appearance and emphasised the longer time to resolution compared with cases of idiopathic SKC. They felt, however, that the condition they observed was not entirely due to thiomersal hypersensitivity. However they did not use topical challenge to confirm the diagnosis.

The inclusion of soft contact lenses as a cause of corneal dendritic lesions has been described by Margulies and Mannis. ${ }^{16}$ In their paper they emphasised the absence of terminal bulbs as a morphological feature of the pseudodendrite lesion associated with soft lens wear. They did not specifically identify thiomersal as the causative factor, but did point out that it, together with chlorbutanol, damages and loosens corneal epithelium. Of interest is their observation of a papillary conjunctival response, in association with the corneal lesions, which they suggested might point to an underlying immunological mechanism. Our patient also demonstrated such a papillary tarsal conjunctival reaction.

The inclusion of the two hard lens wearers with signs of thiomersal hypersensitivity has not been previously reported, and shows that, although it is unusual, they are not prone to developing the condition.' This is probably because of the smaller amounts of thiomersal presented to the eye by the hard lens, resulting in rapid elution by the tears, and also because in the soft lens the stimulus is prolonged as a result of absorption of thiomersal by the material.

An important consideration in the development of thiomersal sensitivity is the changing trend in contact lens hygiene methods; as a result of hypersensitivity reactions there is now a decrease in the use of thiomersal preserved disinfectants, and non-preserved systems have become more popular; these employ non-preserved saline, sodium isocyanate or hydrogen peroxide. However, most soft contact lens cleaners continue to be preserved with thiomersal and may precipitate thiomersal kerratoconjunctivitis. We advocate the use of the two cleaners *'Pliagel' (Alcon Laboratories U.K. Ltd., Imperial Way, Watford, Herts WD2 4YR) or *'Miraflow' (Cooper Vision Optics Ltd., Permalens

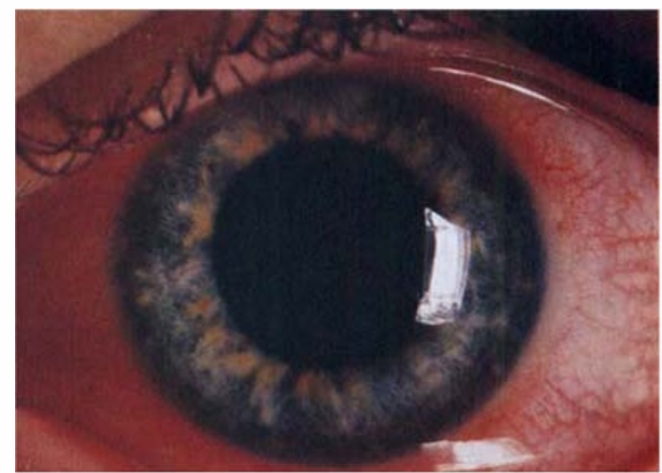

Fig. 6 Characteristic appearance of an eye challenged with topical solution of thiomersal in a sensitised individual.

\footnotetext{
* The authors have no proprietary or commercial interest in these products.
} 
House, 1 Botley Road, Hedge End, Southampton SO3 3HB) which are both thiomersal free, together with non-preserved disinfection systems for patients with thiomersal keratoconjunctivitis once the signs of the condition have regressed.

Management of TKC was avoidance of thiomersal solutions and contact lenses. Steroids had no effect and no other topical medication was used. Patients were advised to avoid lens wear until full resolution of the keratopathy. Thiomersal in their existing hydrogel lenses can be removed by soaking in sterile non-preserved saline. We recommend soaking for a week in daily changes of fresh saline before the lenses are reused.

Our study reveals the wide range of pathological and corneal changes that may evolve from thiomersal hypersensitivity. In cases with atypical features the diagnosis may be suspected if a careful history is taken, but can only be confirmed by topical challenge. We use a solution of $0.005 \%$ thiomersal in isotonic saline for this and the effects last only several days after a positive response has developed. This is manifested as an acute onset of conjunctival hyperaemia in the challenged eye usually within 12 hours of starting to instil one drop four times per day. In some cases, however, it has taken up to 72 hours of this dosage before a response has developed. In all those tested the effect was short lived and without adverse sequelae.

We thank Mr R. J. Buckley FRCS, Director of the Contact Lens and Prosthesis Department, Moorfields Eye Hospital, and Mr P. Wright FRCS, Consultant in charge of the External Disease Clinic, Moorfields Eye Hospital, for permission to report on cases under their care; and Mr P. Hunter FRCS for Fig. 5.
References

${ }^{1}$ Wright $\mathrm{P}$ and Mackie I: Preservative-related problems in soft contact lens wearers. Trans Ophthalmol Soc UK 1982, 102: 3-6.

2 Wilson LA, McNatt J, Reitschel R: Delayed Hypersensitivity to Thiomersal in Soft Contact Lens Wearers. Ophthalmology 1981, 81: 804-5.

${ }^{3}$ Theodore FH: Superior limbic keratoconjunctivitis. Ear Nose Throat J 1963, 42: 25-8.

${ }^{4}$ Rudner EJ, Clendenning WE, Epstein E, et al: Epidemiology of contact dermatitis in North America 1972. Arch Dermatol 1973, 108: 537-40.

${ }^{5}$ Rudner EJ, Clendenning WE, Epstein E, et al: The frequency of contact sensitivity in North America: 1972-1974. Contact Dermatitis 1975, 1: 277-80.

${ }^{6}$ Lepine EN: Results of routine office patch testing. Contact Dermatitis 1976, 2: 89-91.

${ }^{7}$ Moller H: Why thiomersal allergy? Int J Dermatol 1980, 19: 29.

${ }^{8}$ Hansson $\mathrm{H}$, Moller $\mathrm{H}$ : Patch test reactions to merthiolate in healthy young subjects. $\mathrm{BrJ}$ Dermatol 1970, 83: 349-66.

${ }^{9}$ Moller H: Merthiolate allergy: a nationwide iatrogenic sensitization. Acta Dermatol Venereol 1977, 57: 509-17.

${ }^{10}$ Kaufman HE: Problems associated with prolonged wear soft contact lenses. Ophthalmology 1979, 86: 411-17.

${ }^{11}$ Mondino BJ, Salamon SM, Zaidman GW: Allergic and Toxic Reactions in Soft Contact Lens Wearers. Surv Ophthalmol 1982, 26: 337-44.

12 Klareskog L, Forsum U, Malmans U et al: Expression of Ia Antigen-Like Molecules on Cells in the Corneal Epithelium. Invest Ophthalmol Vis Sci 1979, 18: 310.

${ }^{13}$ Shelley WB, Juhlin L: Selective Uptake of Contact Allergens by the Langerhans Cell. Arch Dermatol 1977, 113: 187.

${ }^{14}$ Fuerst DJ, Sugar J, Worobec S: Superior limbic keratoconjunctivitis associated with cosmetic soft contact lens wear. Arch Ophthalmol 1983, 101: 1214-16.

${ }^{15}$ Stenson S: Superior limbic keratoconjunctivitis associated with soft contact lens wear. Arch Ophthalmol 1983, 101: 402-4.

${ }^{16}$ Margulies LJ and Mannis MJ: Dendritic Corneal Lesions Associated With Soft Contact Lens Wear. Arch Ophthalmol 1983, 101: 1551-3. 